\title{
Predicting Depression among Jordanian Adults with Disabilities According to the International Classification of Functioning, Disability and Health: A Pilot Study
}

\author{
Megan Griffin, Bria Mitchell-Gillespie, Hiba Hashim and Rawan AlHeresh * (D) \\ Occupational Therapy Department, MGH Institute of Health Professions, Boston, MA 02129, USA; \\ Megan.e.griffin@MedStar.net (M.G.); BMitchell-Gillespie@MGHIHP.EDU (B.M.-G.); \\ hhashim94@gmail.com (H.H.) \\ * Correspondence: ralheresh@mgh.harvard.edu
}

check for updates

Citation: Griffin, M.;

Mitchell-Gillespie, B.; Hashim, H.; AlHeresh, R. Predicting Depression among Jordanian Adults with Disabilities According to the International Classification of Functioning, Disability and Health: A Pilot Study. Disabilities 2021, 1 , 450-458. https://doi.org/10.3390/ disabilities1040031

Academic Editors:

Ann Alriksson-Schmidt and

Ira Jeglinsky-Kankainen

Received: 18 September 2021 Accepted: 22 November 2021 Published: 24 November 2021

Publisher's Note: MDPI stays neutral with regard to jurisdictional claims in published maps and institutional affiliations.

Copyright: (c) 2021 by the authors. Licensee MDPI, Basel, Switzerland. This article is an open access article distributed under the terms and conditions of the Creative Commons Attribution (CC BY) license (https:/ / creativecommons.org/licenses/by/ $4.0 /)$.

\begin{abstract}
Individuals with disabilities face marginalization in society and are more likely to experience depression compared to the general population. Despite this, the health system in Jordan is not adequately equipped to screen for or manage depression as a comorbid condition. A pilot study using a cross-sectional design was used for this study. Eligible participants were between the ages of 18 and 85, had a physical disability and resided in Jordan. Depression was measured using the Patient Health Questionnaire-9, and risk factors were measured using a sociodemographic survey. Descriptive statistics were used to report on the prevalence of depression and Chi square and Kendall Tau B tests were used to identify relationships between independent variables and depression. The study found that $40.62 \%$ of the sample met the criteria for depression. Those who were not married were found to be at higher risk for depression. The analysis also demonstrated that the number of people in a household was positively correlated with depression. This study fills in gaps concerning the prevalence of depression and its correlates among Jordanian adults with a physical disability. Professionals in Jordan, including rehab specialists, have a role in both screening for and preventing depression, and this study acts as a point of reference for these professionals. This pilot study may initiate larger studies to better understand this relationship in Jordan.
\end{abstract}

Keywords: physical disability; depression; risk factors; Jordan

\section{Introduction}

People living with physical disabilities across the globe are three times more likely to experience depression when compared to their counterparts without a disability [1-3]. Approximately 13\% of the population of Jordan has a disability, and of that portion of the population, $44.2 \%$ have a physical disability [4]. Individuals with disabilities do not have equal access to health care, education, and employment opportunities and experience exclusion from participation in daily activities [5]. The prevalence of depression as a comorbid condition of physical disability, which has been cited as ranging from $27.5 \%$ to 43.6\% [6-13], has been studied in China, Korea, Uganda, Nigeria, Sri Lanka, Germany and Jordan. The association between physical disability and depression has also been connected to various functional and cognitive deficits, including functional dependence, poor quality of life and heightened disability $[14,15]$. Screening and management of depression as a comorbidity of physical disability is needed in Jordan to help minimize the burden of this condition on these individuals and the country as a whole.

In 2011, the World Health Organization (WHO) identified Jordan as a country in need of strengthening their mental health system. As a result, Jordan was chosen to implement the WHO's Mental Health Gap Action Program, which aims to scale up services for mental health disorders, specifically in low and low-middle income countries [16]. One of the tenants of this plan is the early detection and diagnosis of the respective 
country's most commonly occurring mental health conditions, which, in Jordan, includes depression, documented as 3.56\% in 2017 [17,18]. The current literature does not provide a comprehensive understanding of the relationship between depression and physical disability in Jordan. While this relationship has been examined in two recent studies, their study populations do not account for community-dwelling Jordanian adults with physical disabilities $[7,9]$. One study highlighted the prevalence of depression among Jordanians living in assisted living facilities [7], and the second study looked at the prevalence of depression in patients with a chronic medical illness [9], both accounting for only a portion of adults with physical disabilities. Our study uses the definition of disability that is documented in the International Classification of Functioning (ICF): an umbrella term that encompasses impairments, participation restrictions and activity limitations [19]. This expands the generalizability of our results to a larger population in Jordan. The current study highlights the prevalence of depression as a comorbid condition of physical disability in Jordan and helps to identify populations who are at the greatest risk for developing comorbid depression, offering valuable information for early detection and diagnosis.

\section{Materials and Methods}

The study was approved by the Partners Institutional Review Board (IRB) on 8 October 2019 under submission number 2019P001294.

\subsection{Screening}

Convenience sampling, through Facebook announcements, word of mouth and flyers, was used to recruit subjects within Amman, Jordan. The flyer included a phone number to opt in and call the study line. The project coordinator, a licensed physiotherapist, answered the phone and provided study details to anyone who expressed interest in participating.

\subsection{Study Subjects}

The project coordinator answered the phone calls and screened individuals for eligibility by asking the following questions: (1) Do you have a physical disability? (2) Are you between the ages of 18 and 85? (3) Do you reside in Jordan? If a participant answered yes to question 1, the project coordinator administered the Boston University AM-PACTM Basic Mobility Outpatient Routine Short Form (AM-PAC BM) and the Boston University AM-PACTM Daily Activity Outpatient Routine Short Form (AM-PAC DA) patient reported outcome questionnaires that assess activity limitations in the domains of basic mobility and daily activities [20]. These instruments yield a level of impairment, ranging from $0 \%$ impaired to $100 \%$ impaired [20]. Individuals were excluded from the study if their results on both forms yielded $0 \%$ impaired, as this indicates the absence of an impairment, limitation or restriction [21].

If the participants had a score more than $0 \%$ on the AM-PAC and answered yes to both questions two and three, they were enrolled into the study.

\subsection{Data Collection}

A quantitative cross-sectional pilot study was used to examine the prevalence of depression and its risk factors among Jordanian adults with physical disabilities. To understand the risk factors of depression, the research team, comprised of a licensed physiotherapist, a licensed occupational therapist and three Doctor of Occupational Therapy candidates, developed a nine-question survey to collect relevant sociodemographic information (disability, gender, age, education, employment and marital status, personal and household income and number of individuals in household). After subjects were screened over the phone and deemed eligible for participation, the project coordinator scheduled an in-person visit. During this visit, subjects were informed that their participation was voluntary and that their responses would be kept anonymous. The project coordinator provided participants with paper versions of the sociodemographic survey and the Patient Health Questionnaire-9 (PHQ-9), both available in English and Arabic. 


\subsection{Questionnaires}

Eligibility and Impairment Level: Paper versions of the AM-PAC BM and AM-PAC DA, assessments of disability and impairment based on the ICF, were used to screen eligible subjects prior to the start of data collection. Additionally, these forms were used to generate an impairment level for the participants who were eligible for the study. The project coordinator administered these forms.

Demographic Information: Risk factors of depression were assessed using the ninequestion survey that was generated prior to the start of the study. The items, disability, gender, age, education, employment and marital status, personal and household income and number of individuals in household, were consistent with the personal factors outlined in the ICF framework and the most common determinants of depression noted in the literature [7-13,19].

Depression: Presence and severity of depressive symptoms were assessed with the PHQ-9. The PHQ-9 is a nine-item depression scale, with each item corresponding with diagnostic criteria for depression in the Diagnostic and Statistical Manual of Mental Disorders5 [22]. This is a self-report instrument, meaning that each participant read each item and selected a response without any interference from the project coordinator. The PHQ-9 has been found to have better diagnostic accuracy for depression when compared to the Hospital Anxiety and Depression Scale and the World Health Organization Well-Being Index, which are both well-established instruments that screen for depression [23]. This instrument was available in English and Arabic.

Every participant elected to complete the Arabic version of the PHQ-9. This version was found to be a reliable and valid measure to screen for depression in a sample of students in Saudi Arabia [24] and among Lebanese individuals with spinal cord injuries [25]. Furthermore, Sawaya and colleagues found good reliability of the PHQ-9 (Cronbach's alpha $=0.88$ ) when comparing the scores of the PHQ-9 to those of the Psychiatric Diagnosis Screening Questionnaire, among 186 Arabic-speaking psychiatric outpatient patients in Lebanon [26].

\section{Data Analysis}

Frequencies were calculated and tabulated. Before statistical analysis, a PHQ-9 score of 10 or greater (out of 27) was used to dichotomize the results into the presence of depression and the absence of depression. This cutoff score was chosen as it has been found to have sensitivity and specificity for depression of $88 \%$ [23]. The results were further categorized based on the severity of depressive symptoms. Scores of 1-4, 5-9, 10-14, 15-19 and 20-27 on the PHQ-9 signified minimal depression, mild depression, moderate depression, moderately severe depression and severe depression, respectively [27]. Statistical analysis was performed using IBM SPSS ${ }^{\circledR}$ (version 24, Armonk, NY, USA). None of the variables were normally distributed, so nonparametric tests were used.

The cross tabulations were generated between the prevalence of depression vs. impairment level, gender, age category, employment, education and marital status, personal and household income and the number of individuals in the household. Chi square tests were used to determine whether there were correlations between dichotomous variables and depression. Statistical significance was set at $p<0.05$. We also performed Kendall's tau-b $\left(\tau_{\mathrm{b}}\right)$ correlation tests to determine whether there were correlations between ordinal variables; there was statistical significance if $p<0.05$.

\section{Results}

\subsection{Demographic Characteristics}

After screening 33 people, 32 individuals continued to the data collection phase. Background characteristics of the study sample are listed in Table 1 . The sample was $56.25 \%$ male with a mean age of 36 years old. About half of the participants $(53.13 \%)$ attained less than a high school education and, similarly, about half (53.13\%) were unemployed. At the time of data collection, $71.87 \%$ of participants were not married (never married, 
widowed or divorced). Additional characteristics of the cohort are listed in Table 1. Of the total sample included in the present study, 53.13\% reported a disability that fell under the classification of a neurological disorder, and the rest of the classifications are listed in Table 2. The physical impairments observed varied greatly, with most participants having hemiplegia secondary to cerebral palsy and spinal cord injuries.

Table 1. Descriptive characteristics of sample $(n=32)$.

\begin{tabular}{|c|c|c|}
\hline Variable & $n$ & $(\%)$ \\
\hline \multicolumn{3}{|c|}{ AGE (Years) } \\
\hline $18-30$ & 12 & $37.50 \%$ \\
\hline $31-43$ & 12 & $37.50 \%$ \\
\hline $44-56$ & 6 & $18.75 \%$ \\
\hline $57-69$ & 2 & $6.25 \%$ \\
\hline $70-85$ & 0 & $0.00 \%$ \\
\hline \multicolumn{3}{|c|}{ Gender } \\
\hline Male & 18 & $56.25 \%$ \\
\hline Female & 14 & $43.75 \%$ \\
\hline \multicolumn{3}{|c|}{ Marital Status } \\
\hline Single (never married) & 21 & $65.63 \%$ \\
\hline Married & 9 & $28.13 \%$ \\
\hline Widowed & 1 & $3.13 \%$ \\
\hline Divorced & 1 & $3.13 \%$ \\
\hline Separated & 0 & $0.00 \%$ \\
\hline \multicolumn{3}{|c|}{ Education Level } \\
\hline Less than high school & 17 & $53.13 \%$ \\
\hline High school & 7 & $21.88 \%$ \\
\hline Diploma & 3 & $9.38 \%$ \\
\hline Bachelors & 4 & $12.50 \%$ \\
\hline Graduate & 1 & $3.13 \%$ \\
\hline \multicolumn{3}{|c|}{ Employment } \\
\hline Unemployed & 17 & $53.13 \%$ \\
\hline Part time & 4 & $12.50 \%$ \\
\hline Full time & 11 & $34.38 \%$ \\
\hline \multicolumn{3}{|c|}{ Monthly Personal Income } \\
\hline No income & 8 & $25.00 \%$ \\
\hline$<\mathrm{JD} 100$ & 6 & $18.75 \%$ \\
\hline JD 100-200 & 4 & $12.50 \%$ \\
\hline JD 200-250 & 8 & $25.00 \%$ \\
\hline$>$ JD 250 & 6 & $18.75 \%$ \\
\hline \multicolumn{3}{|c|}{ Household Monthly Income } \\
\hline No income & 0 & $0.00 \%$ \\
\hline$<\mathrm{JD} 100$ & 0 & $0.00 \%$ \\
\hline JD 100-200 & 7 & $21.88 \%$ \\
\hline JD 200-250 & 13 & $40.63 \%$ \\
\hline$>$ JD 250 & 12 & $37.50 \%$ \\
\hline \multicolumn{3}{|c|}{ Number of People in Household } \\
\hline 1-2 people & 4 & $12.50 \%$ \\
\hline 3-4 people & 8 & $25.00 \%$ \\
\hline 5 people & 6 & $18.75 \%$ \\
\hline$>5$ people & 14 & $43.75 \%$ \\
\hline
\end{tabular}


Table 2. Classification of participant's self-reported physical disabilities.

\begin{tabular}{ccc}
\hline Classifications of Self-Reported Disabilities & $\boldsymbol{N}$ & $\boldsymbol{\%}$ \\
\hline Neurological Disorders & 17 & $53.13 \%$ \\
Musculoskeletal Disorders & 9 & $28.13 \%$ \\
Amputation(s) & 3 & $9.34 \%$ \\
Congenital Disability (unspecified) & 3 & $9.34 \%$ \\
\hline
\end{tabular}

\subsection{Depression}

As revealed by PHQ-9 scores, depressive symptoms were frequent in individuals with physical disabilities. Eleven participants out of thirty-two screened for depression were considered in the three higher severity groups (moderate, moderately sever and severe depression). The mean PHQ-9 score among the sample was 8.47 (SD = 5.16), with scores ranging from 1 to 21 . Results were then further categorized based on the severity of depressive symptoms (Table 3).

Table 3. PHQ-9 scores * among adults with physical disabilities in Jordan $(N=32)$.

\begin{tabular}{ccc}
\hline Variable & $N$ & $\%$ \\
\hline Minimal Depression (1-4) & 11 & $34.4 \%$ \\
Mild Depression (5-9) & 10 & $31.3 \%$ \\
Moderate Depression (10-14) & 8 & $25.0 \%$ \\
Moderately Severe Depression (15-19) & 2 & $6.2 \%$ \\
Severe Depression (20-27) & 1 & $3.1 \%$ \\
\hline
\end{tabular}

*Values are based on the recommendations listed in the PHQ-9 Questionnaire.

\subsection{Risk Factors of Depression}

We performed a crosstabulation analysis using Chi square tests to determine whether there were associations between each variable and depression. The disability and age variables were dichotomized to be able to use the Chi square test, with $p<0.05$ demonstrating statistical significance. The frequencies of each pair of variables, chi-square statistic, and $p$-values are listed in Table 4. Chi-square statistic tests independence in the likelihood that random chance explains any different between the frequencies and expectation. The only variable that did not demonstrate independence of observing depression as an outcome is marital status $\left(X^{2}=4.5, p=0.033\right)$. This test demonstrated that participants who were not married were more likely to experience depression.

Table 4. Crosstabulation analysis of risk factors of depression.

\begin{tabular}{|c|c|c|c|c|c|}
\hline \multirow{2}{*}{\multicolumn{2}{|c|}{ Risk Factor }} & \multicolumn{2}{|c|}{ Depression } & \multirow{2}{*}{ Chi-Square } & \multirow{2}{*}{$p$-Value * } \\
\hline & & \multirow{3}{*}{$\begin{array}{c}\text { No } \\
10 / 27(37 \%) \\
17 / 27(63 \%)\end{array}$} & \multirow{3}{*}{$\begin{array}{c}\text { Yes } \\
3 / 5(60 \%) \\
2 / 5(40 \%)\end{array}$} & & \\
\hline AM-PAC Daily & $<50 \%$ impaired & & & \multirow{2}{*}{0.922} & \multirow{2}{*}{0.337} \\
\hline Activity & $\geq 50 \%$ impaired & & & & \\
\hline AM-PAC Basic & $<50 \%$ impaired & $8 / 20(40 \%)$ & $12 / 20(60 \%)$ & \multirow{2}{*}{0.009} & \multirow{2}{*}{0.926} \\
\hline Mobility & $\geq 50 \%$ impaired & $5 / 12(41.7 \%)$ & $7 / 12(58.3 \%$ & & \\
\hline \multirow{2}{*}{ Age } & $<44$ & $11 / 24(45.8 \%)$ & $13 / 24(54.2 \%)$ & \multirow{2}{*}{1.080} & \multirow{2}{*}{0.299} \\
\hline & $\geq 44$ & $2 / 8(25 \%)$ & $6 / 8(75 \%$ & & \\
\hline \multirow{2}{*}{ Gender } & Male & $6 / 18(33.3 \%)$ & $12 / 18(66.7 \%)$ & \multirow{2}{*}{0.90} & \multirow{2}{*}{0.341} \\
\hline & Female & $7 / 14(50 \%)$ & $7 / 14(50 \%)$ & & \\
\hline \multirow{2}{*}{ Education Status } & High school degree and less & $10 / 24(41.7 \%)$ & $14 / 24(58.3 \%)$ & \multirow{2}{*}{0.043} & \multirow{2}{*}{0.835} \\
\hline & Degree after high school & $3 / 8(37.5 \%)$ & $5 / 8(62.5 \%)$ & & \\
\hline
\end{tabular}


Table 4. Cont.

\begin{tabular}{|c|c|c|c|c|c|}
\hline \multirow{2}{*}{\multicolumn{2}{|c|}{ Risk Factor }} & \multicolumn{2}{|c|}{ Depression } & \multirow{4}{*}{$\begin{array}{c}\text { Chi-Square } \\
2.281\end{array}$} & \multirow{4}{*}{$\begin{array}{c}p \text {-Value * } \\
0.131\end{array}$} \\
\hline & & \multirow{3}{*}{$\begin{array}{c}\text { No } \\
9 / 17(52.9 \%) \\
4 / 15(26.7 \%)\end{array}$} & \multirow{3}{*}{$\begin{array}{c}\text { Yes } \\
8 / 17(47.1 \%) \\
11 / 15(73.3 \%)\end{array}$} & & \\
\hline Employment & Unemployed & & & & \\
\hline Status & Employed & & & & \\
\hline & Married & $1 / 9(11.1 \%)$ & $8 / 9(88.9 \%)$ & & \\
\hline Marital Status & Not married & $12 / 23(52.2 \%)$ & $11 / 23(47.8 \%)$ & 4.522 & 0.033 \\
\hline Personal Monthly & Less than JD 6 & $7 / 14(50 \%)$ & $7 / 14(50 \%)$ & & \\
\hline Income & More than JD 68 & $6 / 18(33.3 \%)$ & $12 / 18(66.7 \%)$ & 0.907 & 0.341 \\
\hline Household & Less than JD 250 & $10 / 20(50 \%)$ & $10 / 20(50 \%)$ & & \\
\hline Monthly Income & More than JD 250 & $3 / 12(25 \%)$ & $9 / 12(75 \%)$ & 1.943 & 0.163 \\
\hline Number of People & $<$ Five people & $9 / 18(50 \%)$ & $9 / 18(50 \%)$ & & \\
\hline in Household & $\geq$ Five people & $4 / 14(28.6 \%)$ & $10 / 14(71 / 4 \%)$ & 1.499 & 0.221 \\
\hline
\end{tabular}

${ }^{*} p<0.05$ indicates statistical significance.

Furthermore, we performed a Kendall's tau-b test, a nonparametric test to measure the strength and direction of the association of risk factors with the presence of depression and the severity of depression, with $p<0.05$ demonstrating statistical significance. Correlation coefficients and $p$-values for each variable are listed in Table 5 . This test demonstrated that marital status and the number of people in a household are both correlated with depression. Marital status had a moderate negative association with depression $(\mathrm{r}=-0.376, p=0.036)$, and the number of people in a household had a moderate negative association with depression $(\mathrm{r}=-0.32, p=0.05)$ and depression categories $(\mathrm{r}=-0.34, p=0.02)$.

Table 5. Kendall's tau B Analysis.

\begin{tabular}{|c|c|c|c|c|c|c|c|c|c|c|c|}
\hline & & $\begin{array}{c}\text { AM- } \\
\text { PAC } \\
\text { DA }\end{array}$ & $\begin{array}{c}\text { AM- } \\
\text { PAC } \\
\text { BM }\end{array}$ & Age & Gender & $\begin{array}{l}\text { Education } \\
\text { Status }\end{array}$ & $\begin{array}{c}\text { Employment } \\
\text { Status }\end{array}$ & $\begin{array}{c}\text { Marital } \\
\text { Status }\end{array}$ & $\begin{array}{l}\text { Personal } \\
\text { Income }\end{array}$ & $\begin{array}{l}\text { House-hold } \\
\text { Income }\end{array}$ & $\begin{array}{c}N \text { in } \\
\text { House-hold }\end{array}$ \\
\hline PHQ-9 & $\mathrm{r}$ & 0.068 & -0.016 & 0.314 & -0.168 & -0.105 & 0.267 & $-0.376^{*}$ & -0.196 & -0.315 & -0.324 \\
\hline Depression & $p$-Value & 0.677 & 0.922 & 0.99 & 0.349 & 0.530 & 0.137 & 0.036 & 0.223 & 0.064 & 0.051 \\
\hline Depression & $\mathrm{r}$ & 0.091 & 0.033 & 0.113 & -0.195 & -0.255 & 0.116 & -0.154 & -0.110 & -0.258 & $-0.342 *$ \\
\hline Categories & $p$-Value & 0.540 & 0.822 & 0.461 & 0.236 & 0.095 & 0.480 & 0.349 & 0.456 & 0.098 & 0.025 \\
\hline
\end{tabular}

${ }^{*} p<0.05$ indicates statistical significance.

\section{Discussion}

This study fills gaps in the literature concerning the prevalence of depression and its correlates among Jordanian adults who have a disability. By using limited definitions of disability, past studies do not provide a comprehensive understanding of the relationship between depression and physical disability in Jordan. The current study highlights the prevalence of depression as a comorbid condition of physical disability in Jordan and helps to identify populations who are at the greatest risk for developing comorbid depression, offering valuable information for early detection and diagnosis. Additionally, it is worthy to note that physical disabilities accompanied with impairment of brain function or other general comorbid medical conditions might increase the risk of suffering from depressive disorders. The strengths of the current study are that we used valid, reliable and culturally appropriate questionnaires. The utilization of the AM-PAC DA and AM-PAC BM augmented our understanding of each participant's disability; we were able to objectively report on the impairment level of each participant rather than exclusively relying on selfreport. The utilization of the ICF to comprehensively classify a physical disability is also unique to this study and expanded the generalizability of the results to all individuals with physical disabilities in Jordan.

The prevalence of depression reported in this study is consistent with the findings in similar studies [7-13]. Past studies that have evaluated depression among persons with 
disabilities have identified that individuals who were female, older, and single reported higher scores of depressive symptoms $[6,7,9,11,13]$. Our conclusion that unmarried individuals were at greater risk for depression was consistent with the findings noted above. We did not find that a certain gender was correlated with depression. Studies that have found this correlation had larger sample sizes $(5,792$ and 523 females) $[6,13]$, which may account for the difference seen in our study. Conversely, other studies have found that gender had no influence on comorbid depression $[8,10]$. Furthermore, authors of a systematic review found that many studies that have cited gender as a significant risk factor of depression have inflated standard errors, which weakens their results [15]. Variance in the literature could be attributed to how disability was assessed, the country/culture of investigation and the presence of other comorbidities. Overall, the literature is inconclusive, and it is recommended that additional studies, with larger sample sizes, be conducted in Jordan to examine this relationship further. Females make up $41 \%$ of individuals with disabilities in Jordan [4], stressing the importance of examining this risk factor in more depth.

The findings of this study reiterate the marginalization of individuals with disabilities in different facets of society, including education and employment opportunities. About half of the adults had not attained more than a high school education, and nearly half of the sample was unemployed at the time of data collection. This is much higher when compared to the overall high school education ( $98 \%$ ), and unemployment rate in Jordan $(19.2 \%)$ [18]. However, it is important to note that we did not identify why our participants were unemployed. Depression is a common health problem among adults with physical disabilities in Jordan. The findings of this study indicate that $40.62 \%$ of Jordanian adults with physical disabilities have comorbid depression. This is significant for the $13 \%$ of the population of Jordan living with a disability [4]. The severity of depression has been found to significantly influence areas impacting quality of life including general health, social functioning and vitality [10]. Additionally, depression has been found to have an adverse impact on the courses of disabilities, which leads to a poor quality of life, more functional impairments and a higher mortality rate [9].

Scientists and clinicians in Jordan stress the importance of addressing depression as a comorbid condition on a systematic level through appropriate modification of policies and structures [7]. To lessen the occurrence of depression among adults with physical disabilities, we recommend that the structure of the mental health system be revised to include procedures for screening for depression in primary care and rehabilitative settings across Jordan. Developing robust and evidence-based procedures to screen for and reduce depression among this population will contribute to improving the quality of life for these individuals. On a larger scale, this will help to execute the WHO's Mental Health Gap Action Program [16] by addressing the goal of early detection and diagnosis of depression in Jordan.

The findings of this study also have important implications for rehabilitation professionals working in Jordan. The high prevalence of depression noted in this study stresses the importance of training health care professionals who work closely with these individuals, including occupational, speech and physical therapists on how to recognize this issue and respond appropriately. These specialists can help to identify the risk factors of depression in order to intervene and promote increased quality of life. The results of this study may act as a point of reference for these professionals to help identify the risk factors of depression. Rehabilitation professionals also have a role in treating comorbid depression among their patients with physical disabilities. Improvements in activities of daily living have been found to reduce the overall prevalence of comorbid depression [8]. This highlights the need for rehabilitation specialists to develop and implement appropriate habilitative and psychosocial interventions to mitigate and rehabilitate depression among this population.

Despite the important findings, this study has limitations. First, the cross-sectional design does not allow us to determine causal relationships between depression and demographic characteristics. Second, it is possible that some participants were misclassified as 
having depression. It is suggested that using a combination of screening questionnaires and diagnostic interviews yields a definitive diagnosis of depression [28]. Due to limited resources, we were only able to assess depression using a self-report instrument. Nevertheless, we chose to use a valid and reliable instrument to screen for depression and followed the recommendations in the literature when deciding the appropriate cutoff score. Data collection involved translation by bilingual team members, which may have resulted in information that is inaccurate. We addressed this barrier by involving two researchers who were fluent in both Arabic and English. Due to unforeseen circumstances associated with the spread of the COVID-19 virus and the ethical obligation to terminate recruitment, this study was limited to a small sample size. However, this pilot study provides valuable information for implementing studies. We recommend a further full-powered study with a similar methodology with a larger group of participants in the future.

\section{Conclusions}

Our study revealed a high prevalence $(40.62 \%)$ of depression in a sample of Jordanian adults with physical disabilities. Participants who were not married were more likely to screen for depression. It is necessary to screen for depression across health care facilities in Jordan and train professionals to prevent and mitigate these symptoms in patients with physical disabilities.

Author Contributions: Conceptualization, M.G. and R.A.; methodology, M.G. and R.A.; software, M.G.; validation, M.G.; formal analysis, M.G., B.M.-G., H.H. and R.A.; investigation, M.G., B.M.-G., H.H. and R.A.; resources, M.G., B.M.-G., H.H. and R.A.; data curation, M.G., B.M.-G., H.H. and R.A.; writing—original draft preparation, M.G., B.M.-G., H.H. and R.A.; writing-review and editing, M.G., B.M.-G., H.H. and R.A.; visualization, M.G., B.M.-G., H.H. and R.A.; supervision, R.A.; project administration, R.A.; All authors have read and agreed to the published version of the manuscript.

Funding: This research received no specific grant from any funding agency in the public, commercial or not-for-profit sectors.

Institutional Review Board Statement: The study was conducted according to the guidelines of the Declaration of Helsinki, and approved by the Partners Institutional Review Board (IRB) on 8 October 2019 under submission number 2019P001294.

Informed Consent Statement: Informed consent was obtained from all subjects involved in the study.

Data Availability Statement: The data that support the findings of this study are openly available in Harvard Dataverse at https:/ / doi.org/10.7910/DVN/997NHU, accessed on 21 November 2021.

Acknowledgments: We would like to thank all of the participants in this study and our onsite project manager, Ola Hiyari.

Conflicts of Interest: The authors declare no conflict of interest.

\section{References}

1. Hughes, R.; Swedlund, N.; Petersen, N.; Nosek, M. Depression and women with spinal cord injury. Top. Spinal Cord Inj. Rehabil. 2001, 7, 16-24. [CrossRef]

2. Turner, R.J.; Beiser, M. Major depression and depressive symptomatology among the physically disabled: Assessing the role of chronic stress. J. Nerv. Ment. Dis. 1990, 178, 343-350. [CrossRef] [PubMed]

3. US Department of Health and Human Services. Healthy People Final Review 2010; 2012. Available online: https://www.cdc.gov / nchs/data/hpdata2010/hp2010_final_review.pdf (accessed on 2 February 2020).

4. Thompson, S.; Institute of Development Studies. The Current Situation of Persons with Disabilities in Jordan. 2018. Available online: https:/ / assets.publishing.service.gov.uk/media/5bb22804ed915d258ed26e2c/Persons_with_disabilities_in_Jordan.pdf (accessed on 2 February 2020).

5. World Health Organization. World Report on Disability. 2011. Available online: https://apps.who.int/iris/bitstream/handle/10 665/70670/WHO_NMH_VIP_11.01_eng.pdf?sequence=1 (accessed on 10 February 2020).

6. Noh, J.-W.; Kwon, Y.D.; Park, J.; Oh, I.-H.; Kim, J. Relationship between Physical Disability and Depression by Gender: A Panel Regression Model. PLoS ONE 2016, 11, e0166238. [CrossRef] [PubMed] 
7. Almomani, F.M.; Bani-issa, W. The incidence of depression among residents of assisted living: Prevalence and related risk factors. Clin. Interv. Aging 2017, 12, 1645-1653. [CrossRef] [PubMed]

8. Gyagenda, J.O.; Ddumba, E.; Odokonyero, R.; Kaddumukasa, M.; Sajatovic, M.; Smyth, K.; Katabira, E. Post-stroke depression among stroke survivors attending two hospitals in Kampala Uganda. Afr. Health Sci. 2015, 15, 1220-1231. [CrossRef] [PubMed]

9. Hamdan-Mansour, A.M.; Ghannam, B.M.; Abeiat, D.D.A.; Badawi, T.H.A.; Thultheen, I.N.; Shamali, I.M. Predicting Depression among Jordanian Patients Diagnosed with Physical Illnesses. Psychology 2014, 5, 2120. [CrossRef]

10. Körner, S.; Kollewe, K.; Abdulla, S.; Zapf, A.; Dengler, R.; Petri, S. Interaction of physical function, quality of life and depression in Amyotrophic lateral sclerosis: Characterization of a large patient cohort. BMC Neurol. 2015, 15, 84. [CrossRef] [PubMed]

11. Ojagbemi, A.; Akinyemi, R.; Baiyewu, O. Cognitive dysfunction and functional limitations are associated with major depression in stroke survivors attending rehabilitation in Nigeria. NeuroRehabilitation 2014, 34, 455-461. [CrossRef] [PubMed]

12. Senarath, U.; Wickramage, K.; Peiris, S.L. Prevalence of depression and its associated factors among patients attending primary care settings in the post-conflict Northern Province in Sri Lanka: A cross-sectional study. BMC Psychiatry 2014, 14, 85. [CrossRef] [PubMed]

13. Sun, N.; Lou, P.; Shang, Y.; Zhang, P.; Wang, J.; Chang, G.; Shi, C. Prevalence and determinants of depressive and anxiety symptoms in adults with type 2 diabetes in China: A cross-sectional study. BMJ Open 2016, 6, e012540. [CrossRef] [PubMed]

14. Deschênes, S.S.; Burns, R.J.; Schmitz, N. Associations between depression, chronic physical health conditions, and disability in a community sample: A focus on the persistence of depression. J. Affect. Disord. 2015, 179, 6-13. [CrossRef] [PubMed]

15. Ojagbemi, A.; Akpa, O.; Elugbadebo, F.; Owolabi, M.; Ovbiagele, B. Depression after Stroke in Sub-Saharan Africa: A Systematic Review and Meta-Analysis. Behav. Neurol. 2017, 2017, 4160259. [CrossRef] [PubMed]

16. World Health Organization and Ministry of Health. WHO-AIMS Report on Mental Health System in Jordan. 2011. Available online: https:/ /www.who.int/mental_health/evidence/mh_aims_report_jordan_jan_2011_en.pdf?ua=1 (accessed on 9 February 2020).

17. The Hashemite Kingdom of Jordan. National Mental Health Policy. 2011. Available online: https://www.mhinnovation.net/ sites/default/files/downloads/innovation/reports/National-Mental-Health-Policy-Jordan.pdf (accessed on 11 February 2020).

18. Ritchie, H.; Roser, M. Mental Health. 2020. Available online: https:/ / ourworldindata.org/mental-health (accessed on 1 April 2020).

19. World Health Organization. Towards a Common Language for Functioning, Disability, and Health ICF. 2002. Available online: https://www.who.int/classifications/icf/icfbeginnersguide.pdf (accessed on 8 February 2020).

20. Shirley Ryan Ability Lab. Activity Measure for Post Acute Care. Available online: https://www.sralab.org/rehabilitationmeasures/activity-measure-post-acute-care (accessed on 24 March 2019).

21. The Medicare Learning Network. Quick Reference Chart: Descriptors of G-Codes and Modifiers for Therapy Functional Reporting. Available online: https:/ / www.cms.gov/outreach-and-education/medicare-learning-network-mln/mlnproducts / downloads /g-codes-chart-908924.pdf (accessed on 24 February 2019).

22. Löwe, B.; Gräfe, K.; Zipfel, S.; Witte, S.; Loerch, B.; Herzog, W. Diagnosing ICD-10 depressive episodes: Superior criterion validity of the Patient Health Questionnaire. Psychother. Psychosom. 2004, 73, 386-390. [CrossRef] [PubMed]

23. Kroenke, K.; Spitzer, R.L. The PHQ-9: A New Depression Diagnostic and Severity Measure. Psychiatr. Ann. 2002, 32, 509-515. [CrossRef]

24. AlHadi, A.N.; AlAteeq, D.A.; Al-Sharif, E.; Bawazeer, H.M.; Alanazi, H.; AlShomrani, A.T.; Shuqdar, R.M.; AlOwaybil, R. An arabic translation, reliability, and validation of Patient Health Questionnaire in a Saudi sample. Ann. Gen. Psychiatry 2017, 16, 32. [CrossRef] [PubMed]

25. Summaka, M.; Zein, H.; Abbas, L.; Elias, C.; Elias, E.; Fares, Y.; Naim, I.; Nasser, Z. Validity and Reliability of the Arabic Patient Health Questionnaire-9 (PHQ-9) in Spinal Cord Injury Patients in Lebanon. World Neurosurg. 2019, 125, e1016-e1022. [CrossRef] [PubMed]

26. Sawaya, H.; Atoui, M.; Hamadeh, A.; Zeinoun, P.; Nahas, Z. Adaptation and initial validation of the Patient Health Questionnaire9 (PHQ-9) and the Generalized Anxiety Disorder-7 Questionnaire (GAD-7) in an Arabic speaking Lebanese psychiatric outpatient sample. Psychiatry Res. 2016, 239, 245-252. [CrossRef] [PubMed]

27. Spitzer, R.L. Patient Health Questionnaire: PHQ; New York State Psychiatric Institute: New York, NY, USA, 1999; Available online: https: / / search.library.wisc.edu/catalog/999907635102121 (accessed on 2 February 2020).

28. Thombs, B.D.; Kwakkenbos, L.; Levis, A.W.; Benedetti, A. Addressing overestimation of the prevalence of depression based on self-report screening questionnaires. CMAJ 2018, 190, E44-E49. [CrossRef] [PubMed] 